\section{THE CROONIAN LECTURES on}

\author{
THE P ULSE.
}

Welivered at the Royal College of Physicians of London, March, 1887.

Bx W ILLIAN H. BROADBENT, M.D., F.R.C.P., Physician to St. Mary's Hospital ; Consulting Physician to the London Fever Hospital; and President of the Clinical Society.

LECTURE III.

Mr. President and Gentlemen,-Examples of the effect upon the pulse of diseases of the nervous system might be multiplied indefinitely, but I propose to ask your attention to the converse of this, namely, to effects produced on the brain by abnormal conditions of the circulation.

The nutrition of the brain, as of all parts of the body, is dependent upon the supply of an adequate amount of healthy blood, but the functional activity and efficiency of the brain are even more dependent upon the blood-supply than its nutrition, and are influenced by it to an extraordinary degree, so that blood which would maintain the structural integrity of the brain might be altogether unfit to minister to its fucctions. The presence of alcohol in the blood, for example, does not interfere with the nutrition of the nerve-centres, but it deanges their action, and poisons generated in the system or retained excretory matters may have a similar effect. The liberation of nerve. force has been represented as an explosive action, and this implies the presence in the nerve-cells of a substance ready, on the application of the proper stimulus, to combine instantly with the oxygen brought by the blood. The formation of such materia!, its maintenance at a given state of chemical tension, so to speak, which differs in the dif ferent centres, in the cortex, in the central ganglia, and in the medulla and cord, is not paralleled by any other nutritive operation. There is, moreover, the further requirement of a due supply of oxygen.

An illustration of the relation between cerebral functions and the circulation is seen in the anæmia of the cortex of the hemispheres during sleep. This bloodlessness is essential to sleep, and, if it can be induced, sleep follows. It is not clear, however, whether it is primarily the shutting off of the blood which determines and compels sleep, or the exhaustion of the nerve-cells and the periodic cessation of activity organised in the experience of the nervous system by the succession of night and day, which disposes to sleep, and provides for it by causing the cortical arterioles to contract so as to produce the anæmia.

Sleeplessness is extremely common, and may be due to a great variety of causes, to excitement during the day or in the evening, to grief or anxiety, to exhaustion or over-work, especially work of an intellectual kind carried on far into the night, to late meals, errors in diet, indigestion and flatulence or other functional derangements, to tea or coffee. On the recognition and removal or avoidance of any such disturbing influences the sleeplessness will disappear.

We are trequently called upon, however, to relieve habitual sleep lessness which cannot be referred to any of the above causes, and in many instances it is associated with abnormal conditions of the circulation. Not to speak of heart-disease, all forms of which are prone to disturb or interfere with sleep, or of palpitation, which is apt to come on at night, there are two distinct conditions of the circulation to which sleeplessness is very often due. One is the state of high tension, absolute or virtual. There may be little beyond the sleeplessness of which the patient complains, or the loss of sleep may merely be one of a long train of oymptoms-depression, apprehension, loss of memory, want of energy, and the like. The artery at the wrist may be large or small, but it is full between the beats, and can be rolled under the finger; the pulse may be long and gradual, or somewhat abrupt in its beat, and ending suddenly, according to the condition of the heart.

It appears to me probable that the cause of the sleeplessness in the class of cases under consideration is the inability of the arterioles of the cerebral cortex to overcome the excessive blood-pressure within them, and shut off the blood so as to induce the anæmia requisite for sleep.

In common with the peripheral arteries generally, their muscular walls are all day putting forth an abnormal amount of contractile $\lfloor 1371$ force, and at night are unequal to the further task of exercising sufficient additional contraction to narrow the channels to sleeping point. In such cases sleep is often at once procured by reducing the general arterial tension, and a mild mercurial aperient is the most. efficient hypnotic. The cases are numbered by scores in which I have found this line of treatment efficacious in habitual sleeplessness, many natients having been rendered independent of sedative draughts to which they had been driven. At first it is not unusual for the patient to suppose that a new and powerful opiate has been given, and the good effects do not wear out by repetition. It is not by unloading the bowel that the aperient acts ; it has often to be given to induce sleep when the bowels are acting regularly and freely, and it is to be remarked that it is within an hour or two of the pill having been taken, and many hours before an evacuation results, that the patient sleeps. The general intra-vascular pressure being lowered, the cortical arterioles are no longer resisted by the pressure within them, and they can respond to the call for exclusion of the blood from the hemispheres.

The desired effect may often be attained by other means-by a hot bath, by the sitz-bath and wet bandages employed in hydropathic establishments, by standing in cold water and then rubbing the feet well with a rough towel, and by a variety of other measures, which either relax the cutaneous vessels generally and so lower the arterial tension, or set up a local hyperæmia which diverts the blood from the head. A method of courting sleep, which I have known to be adopted by subjects of high arterial tension, is to lie with the back of the neck on a hot water bottle. Sometimes, however, the object is defeated by some collateral effect, as, for example, when a hot bath sets the heart beating violently, and, when successful, such measures often having the defect of dealing with the effect and not removing the eause.

An opposite state of the circulation, extremely low tension, may be the cause of sleeplessness. It is more common after middle life and in men of sedentary occupation, and may be traceable to overwork or anxiety, or simply to close attention to business and neglect of holiday. It is not often that there is excess in eating or drinking; more frequently the patient is distinctly abstemious. Without apparent cause he begins to lose his sleep at night. In the day-time, however, he is disposed to sleep, and, not infrequently, unless engaged in actual work, he drops asleep at any moment; not only after dinner, when sleep in such cases is irresistible, but when reading his newspaper in the morning after breakfast. Not unnaturally, it is supposed that the after-dinner nap spoils the night's rest, or that the bad night causes the drowsiness during the day, but attempts to rectify this state of things by preventing sleep after dinner and similar measures fail. The sufferer may try to secure a good night by going to bed soon after dinner, but at this time, as at the usual hour for retiring, as soon as he lies down he is wide awake and so remains. After a time it will be discovered that it is position which induces or prevents sleep. In the sitting posture slee? is almost irresistible, in the recumbent position almostimpossible. The patient will sometimes get out of bed in the night and sleep in his chair, as we see sufferers from advanced heart disease. Undar such circumstances I have found the circulation unstable, the pulse, during the same interview, at one time short and weak, and at another presenting the characters of virtual tension-that is, full between the beats, but compressible, sudden and not sustained, and the power of the heart low. There is a want of tone in the muscular tissues of the arterioles and a want of driving power in the heart, and the distribution of the blood thus becomes unduly influenced by gravity. In the sitting position, when the heart is not stimulated by exercise, nor afflux of blood to the convolutions determined by mental work, the blood is not lifted to the height of the brain with sufficient energy, the contractile tendency of the cortical arteries is not opposed by intra-vascular pressure, and sleep-producing anæmia of the hemispheres results. On the other hand, this same want of tone in the arterioles allows them to be distended by the increased pressure of the blood within them, which attends the horizontal position. In such cases change of air will often put an end to the sleeplessness at once, and the appropriate remedies are vascular. tonics, iron, acids, strychnine, and digitalis.

Convulsions and the Pulse.-Conditions of the circulations indicated by the pulse are unquestionably among the causes of convulsions. The brain responds by convulsions to a great variety of disturbing influences-to direct irritation of the cortex, as has been demonstrated by experiment, and is illustrated by spiculæ of bone, tumours, menin geal hæmorrhage, etc.; to irritation of lower centres and tracts, such as the cerebellum and its superior peduncles, or in the interpeduncular space, and to reflex irritation of the most varied kind; to poisons of 
different kinds, but especially to the poisons of specific fevers, such as small-pox, scarlatina, or measles.

With regard to such causes of convulsions as concern us from their relation with the pulse, experiment has shown that convulsions may attend exactly opposite states of the circulation. The final phenomena of death from rapid hæmorrhage, when the cerebral vessels are empty and the pressure presumably at a minimum, are convalsions, and convulsions occur in death by asphyxia, when the blood-pressure is high. These extremes probably meet in the production of stasis of the cerebral circulation, and it seems to me that we have clinical illustrations of convulsions produced by unduly high arterial tension on the one hand, and by excessively low arterial pressure on the other.

The cranium being a closed cavity, the total volume of its contents, brain-structures, blood, and cerebro-spinal fluid, must be a constant quantity. The effusion of liquid into the ventricles or meninges; often found after death, shows that some sort of compression and shrinkage of the brain-substance is possible, but whether this is at the expense of the blood in its capillaries, or of fluid in the perivascular spaces, or of interstitial fluid, cannot be stated definitely; since, however, there may be greater appearance of vascularity in the sulci and white matter at the same time, it cannot be by exclusion of blood that the intraventricular or subarachnoid fluid makes room for itself. But whatover may be the way in which the brain-substance accommodates itself to effused fluid, it is not to be supposed that it is compressd into smaller compass at each pulsation of its vessels. This being so, either the blood must escape by the veins exactly in the same amount and at the same time as it enters by the arteries, and therefore more or less in a pulsatile manner, or there must be some shifting to and fro of cerebro-spinal fluid between the cranial and spinal cavities, that is, the expulsion of a certain amount of flaid from the cranium into the spinal canal with each arterial pulsation, and a gradual reflux in the interval. But the spinal canal is also a closed cavity, and, although its walls, being only ligamentous between the vertebræ, are not so rigid as the bones of the skull, there is no provision for variations in its capacity, while the arteries of the cord and its meninges will be distended at the same moment as those of the brain, which would tend to resist the passage of fluid from the cranial to the spinal cavity. The to-and-fro movement of cerebro-spinal fluid, then, which has been postulated as an easy explanation of some of the difficulties with regard to the cerebral circulation, cannot be admitted, and it must be the case that, exactly as the blood enters the cranium by the carotids and vertebral arteries, it leaves it by the internal jugular veins. The movement of blood in the internal jugulars has, in fact, been found to be pulsatile. I have pointed out in my first lecture that neither the expansion of the arteries nor the onward movement of the blood is as great as is usually supposed, and there is a provision both in the carotids and vertebrals for moderating the current (which is present in a still more marked degree in animals which feed on the ground), but, with all this, the intra-cranial circulation is carried on under peculiar difficulties, and any interference with the general circulation may tell with special influence upon it.

In the eye the circulation is under much the same conditions as in the brain, in so far as the effects of high intra-vascular pressure are concerned-the sclerotic being unyielding-and the changes which are known to take place in the retina in renal disease have more than a mere diagnostic or clinical interest. They throw light on changes occurring in the brain, and study and investigation in this direction will be well repaid. We have retinal as we have cerebral hæmorrhages. It is possible, again, that there are intra-cranial conditions like in kind to those of the choked disc, if different in degree, and there may be changes in the brain substance corresponding to the white spots in the retina. All these are, in iny opinion, attributable to pressure effects rather than to blood deterioration. Glaucoma, which, in my small experience, has always been associated with high pulse tension, and which I believe to be an effect of intra-vascular pressure, may also have its analogue in the cranium.

Be this as it may, there cannot be any doubt that the intracranial pressure varies with each heart-beat and with all variations of the blood-pressure in the arteries or veins. The brain would pulsate if it could, and does pulsate whenever a part of the cranial vault is abseut or yielding. The fontanelle of an infant beats with the pulse, rises and falls with the respiratory movements, is tense and prominent when the child cries, hollow when it is asleep, is full and firm when the child is well, depressed when it is weakened, say by diarrhœa, and the same fluctuations can be seen at a trephine opening in the adult skull. The same pressure fluctuations which give rise to the pulsation and varying tension of the fontanelle will, in a greater or less degree, tend to compress the cortex of the hemispheres against the vault of the cranium, and it is conceivable that the compression might be such as to interfere with the free passage of blood through the pia mater of the convolutions, or to flatten, more or less, the veins which run on the surface of the hemispheres to the longitudinal sinus -it might, indeed, arrest momentarily the cortical circulation. Blood stasis in this situation, from pressure against the cranial vault, must occur when the convolutions are flattened by effusion in to the ventricles in tubercular meningitis, and it is not unreasonable to suppose that the convulsions and loss of consciousness which mark the final stage of this disease coincide with this event. But there are not wanting evidences of the production of momentary arrest of the cerebral circulation by comparatively slight temporary causes. Some years since I met, at a scientific congress, a distinguished French surgeon who, at the age of fifty-five or sixty, was suffering from whooping-cough; at every paroxysm he dropped down unconscious; and I have met with a case in whish, for many years, the patient, who was the subject of chronic bronchitis, fell down with momentary loss of consciousness and slight convulsion whenever he coughed, and this too quickly for the production of cyanosis. In these cases the obstruction would take effect by backward pressure through the jugulars. Short of any such result as loss of consciousness, it is not uncommon for the respiratory concussion attending the act of coughing to be felt as severe pain in the head.

A gradual encroachment on the capacity of the cranial cavity would exert a very similar influence on the cortical circulation by pressure from without to that which I am assuming might be the result of pressure from within, and the effects of such an occurrence are exemplified in the following case seen with Mr. Brend, of Kensington. The patient, a lady, aged about 36 , had enjoyed good health all her life, and had had children, when she began to be subject to fits. She was seen by various physicians, and different opinions were given as to the character of the attacks - for the most part they were considered to be hysterical. She was subjest to headache and confusion of thought, but not more so than is common; there was no vomiting. When I was consulted, she looked well, was stout, and had a good colour, and was discharging all her family and social duties, though with effort. Just as she had taken off her dress to facilitate an examination of the chest, an attack came on which we were so fortunate as to witness. She turned pale and lost consciousness, there was a slight quiver of the muscles of the face and movements of the arms, bu the most striking fact was a complete iarrest of the heart for a sufficient time to cause us serious anxiety. This prevented us from adopting the opinion previously given that the fits were of no importance, and our prognosis was soon afterwards verified by the patient's death in one of the attacks. The only morbid appearance found was an extraordinary thickening of the frontal bone, which was as dense as ivory, and more than half an inch thick at the lower part, gradually thinning towards the coronal suture. The inner surface was smooth, and the dura mater little changed.

The following are examples of convulsions associated with high pulse-tension.

A medical friend called on me one morning ten years since, at the bidding of his wife, as he told me laughingly. He said he had had some sort of fainting attack, but that he was perfectly well. His forehead, however, was covered with minute ecchymoses, and it was obvions that he had had severe convulsions. He was 42 years of age, had lived freely and carelessly, but was not intemperate ; there was a doubtful history of syphilis, and twelve months previously he had had a severe fall on his head. He had very high tension of the pulse. I was summoned to him early next morning, and found that he had gone from one convulsion into another for the greater part of the night, of so severe a character that artificial respiration was required at the end of each attack. I had no hesitation in attributing the convulsions, the first and last he had ever had, to the state of the circulation, and the patient was bled to about thirty ounces. He had the last convulsion as the blood was flowing, made a rapid and complete recovery, and has had no attack since.

In another very similar case, also that of a medical man, aged about 50 , seen three years since, I did not see the convulsions, which had been very violent, but the assurance I felt justified in giving, from the history and from the state of the pulse, that no recurrence need be apprehended if the tension were reduced by appropriate diet and treatment, has been verified up to the present time, and the patient has improved greatly in general health.

A third case, that of a lady, aged at that time 49 , came under my observation in May, 1878. She was stout, over-fed, and had marked tension of the pulse, which appeared to be taking effect on the left ventricle. She was said to have albuminuria, but I found no slbumen in the urine, and the specific gravity was normal. I was consulted on account of severe and repeated convulsive attacks of an epileptic 
character, which came on two or three times a week, sometimes in series of six or seven. The convulsions speedily ceased under treatment by saline aperients, which lowered the vascular tension, and she remained free from them until 1885, when she had cerebral hæmorrhage and hemiplegia, and she died late in 1886, from another attack, attended with convulsions.

In December, 1885 , a gentleman, aged 65, working hard as a teacher of music, consulted me on account of convulsions, which had occurred in the previous July before breakfast, and on December 1st after dinner. On the latter occasion there had been sudden loss of consciousness, and a fall, in which a cut on the head had been sus. tained. He looked and felt well, had a fresh colour, the appetite was good, and the bowels regular, and he slept well. The urine was copious, had a specific gravity of 1015 , and contained neither albumen nor sugar. The pulse was tense, bat short, the first sound of the heart short, the aortic second accentuated. The condition of the circulation was that of virtual tension. A mild blue and colocynth pill was ordered to be taken once a week and arsenic and nux vomica prescribed as a tonic. In March, while stooping after a heavy meal, he fell forwards and was unconscious for a few seconds, and this is the only attack he has had.

Other illustrations might be given, but I will only refer to one more, which I related in my address as President of the Medical Section of the Brighton meeting of the British Medical Association. The patient, aged 37, came under my observation in November and December, 1885, suffering from headache and oppression, and was found to have an unusual degree of arterial tension, and shortly afterwards I was called to him in consultation with Dr. Wilbe, when he was almost unconscious, overwhelmed apparently by a sense of pres. sure in the head, and exhibiting violent synchronous contractions of the pectoral and abdominal muscles. The pressure in the arteries was extreme, and the incompressibility of the pulse surpassed anything in my experience. The patient was bled with good effect, but repeated free calomel purging was needed to bring down the tension and complete the recovery. There was an early stage of contracting kidney in this case, but no such change as to give rise to uræmia.

The convulsions which sometimes occur months or years after an attack of hemiplegia have, in my experience, always been associated with high tension, and have often been prevented from recurring by treatment directed against this. In a brain damaged by hæmorrhage, which has left a cicatrix, the circulation is more easily deranged to a point attended with symptoms than before.

It may be considered as proved that, in some way, such a modification of the cerebral circulation may be produced by high arterial tension as is capable of giving rise to convulsions; and, as I have already said, it is, in my opinion, through the intervention of high arterial tension that uræmic convuisions are brought about. There may be extreme uræmic intoxication, ending fatally by coma, without convulsions ; urea, the ammoniacal products of its decomposition, and the forms of nitrogenised waste which may be supposed to accumulate in the blood in renal disease, do not excite convulsions when injected into the blood.

These facts seem to show that it is not simply and directly by the presence of renal impurities in the blood that the convulsions are excited. On the other hand, there are the facts that uræmic convulsions are most common in that form of kidney disease in which high arterial tension is most marked-the contracted granular form-and that they do not occur in the absence of, at any rate, a certain degree of tension. But the consideration which carries, perhaps, the greatest weight, is the remarkable effect of blood-letting in uræmic convulsions. The status epilepticus is cut short, the coma abbreviated, and associated symptoms relieved. These effects, which are remarkably constant, cannot be from elimination of toxic matter; the blood left in the vessels will be both more watery and more impure from resorption of liquid from the tissues. They can scarcely have any other cause than diminution of the volume of blood and lowered pressure in the vessels.

In acute renal dropsy with convulsions a venesection may not only arrest the convulsion, but may exercise a favourable influence on the disease, and in chronic Bright's disease, nearing a fatal termination, bleeding may prolong life and change altogether the mode of dying from convulsions and coma to a quiet asthenia.

Illustrations of the association of convulsions with low arterial tension are less common, but $I$ have seen in a child of 12 , belonging to a family in which the pulse-tension is low, and who has the family pulse, a momentary convulsion during vaccination. There was no nervousness or fear, but, on the contrary, the operation was regarded with interest. The child, however, dropped as if shot, with a slight general convulsion, and then immediately got up again, looking very much astonished, but not otherwise affected.
In another low-tension individual, a young man of remarkable courage; the application of a few leeches to the ankle, which had been injured rather severely, was followed by syncope, emergence from which was attended with brief but shar $\rho$ general convulsions.

In the following case, seen first with Dr. Godson, Mr. White, and Dr. Kane, and later with Dr. Kane, the association of convulsions with an extremely low pulse-tension and their dependence upon a feeble circulation seemed to be very clear. The notes are by Dr. Kane.

"The patient, a lady, aged about 26, florid and healthy, was confined August 3rd, 1886. Second confinement; previous one normal. Three weeks before labour had phlebitis of right saphena vein, with great pain, some pyrexia, but little cedema ; it terminated favourably in about fourteen days, leaving a hardened vein. Labour natural. Some membranes were retained, but gave no signs of their presence till the seventh day, when the discharge became offensive. There was pain over the abdomen and slight rise of temperature: The uterus was washed out with Condy's fluid, and the next morning the pain had disappeared. A rigor followed the injection of the uterus, and the temperature rose to $105^{\circ} \mathrm{F}$. The discharge continuing foetid, injections were repeated, and the retained membranes came away. An offensive discharge persisted for a day or two, after which the lochia became sweet and normal. The milk stopped fourteen days after labour.

"From the first rigor dates the commencement of the high temperature. Daily it rose to 104,105 , and even 106 ; but, at the same time, it invariably fell to normal at one time every twenty-four hours. There was no regularity in the periods of high and low temperature; some days it would rise rapidly to the maximum, and after an hour would fall as rapidly : on other days it would remain about normal most of the day. The pulse, always weak, was most rapid and irregular, sometimes quite uncountable. Terrible rigors occurred almost daily, generally commencing when the temperature was low, and invariably followed by rapid rise of temperature. The patient suffered comparatively little from the high temperature, had no delirium, and seemed to be more comfortable than when the temperature was normal, though the weathor at the time was extremely hot. On the seventeenth day after labour, phlebitis occurred in the right saphena. This phlebitis continued to give trouble, on and off, for another ten days, and there was considerable swelling of ankle.

"The rigor and temperature continuing unchanged, in spite of all remedies, it was decided, on September 15th, forty-three days after labour, to remove her to another house. There was the more pressing reason for this, that an expert had decided that sewer-gas entered the house. She bore the move well, and for a time seemed to improve. She had some slight shiverings, but no more rigors. For several days the temperature never rose above 102 . She had numerous small boils. On the sixth day after the move (September $21 \mathrm{st}$ ) her temperature rose suddenly to 106, fell again to normal, and in the evening rose again to 104 . She did not seem worse in any other way. About 10 P.M. I was suddenly summoned, the messenger saying she was dying. I found her sitting up in bed, with very flushed face and widely-dilated pupils; she appeared quite unconscious, with gasping respiration, and very rapid and tumultuous action of the heart. I diagnosed cardiac embolism. Soon after my arrival she fell back and passed into a terrible convulsion, face turned to the left, arm drawn up, and legs extended and rigid. This lasted some minutes, and was followed in half an hour by a second, and again, before morning, by a third. After the convulsions, the left arm seemed paralysed, but this passed off before morning. She was very prostrate, and moaned a great deal, and, if moved, screamed out and applied her hand to the right side of her head. No inequality of pupils; passed urine and motions in the bed. Mental condition very excited, at first aphasic and unintelligible, afterwards noisy, singing, crying, and praying. After this she sank into a very depressed coudition, with constant tendency to failure of the heart. The slightest attempt to sit up caused giddiness and slight convulsion. She had to be constantly watched, and at times even artificial respiration had to be resorted to. Face sunk, and whole aspect of impending death; temperature 104; pulse utterly uncountable. Such was her state on September 26 th, fiftyfour days after labour.

"The case was considered hopeless, but it was determined to persevere steadily with large doses of tinct. ferri mur. and digitalis in gradually increasing doses. The result was highly satisfactory. The patient rallied and steadily progressed from this date. Quantities of small boils appeared, and gave her mich pain. Delirium continued for some days, and she had some delusions. The slightest attempt to sit up brought on a slight convulsion. The temperature never again rose above 102, and in a very few days fell to normal, and remained 
at that. Ten days after the first convulsion she had another severe one, followed by a return of the mental disturbance. She was free from attacks, except slight ones, for about a fortnight, when she had another severe attack, then an interval of three weeks, and a series of terribly severe ones lasting six hours. It being thought that the convulsions might be due to an attempt to restore the catamenia, attention was turned in that direction, and after some time the menstrual flow was established, ushered in by several slight convulsions. All this time her progress to health had been continuous, with the exception of a slight pneumonic attack, with some fever and congh, which disappeared after she had coughed up a patch of deep rusty mucus. She had numerous slight convulsive attacks, generally on waking up from sleep; but they left no after-effects, and she steadily improved until January 26 th, six months from the commencement of her illness, when she was well enongh to be moved to Hastings, and underwent the journey without any fatigue or after bad result. She is now in capital health ; but her pulse has a tendency to become irregular, and she has occasional attacks of threatened convulsions."

The above account has been supplied to me by Dr. Kane. I first saw the case on October 9th, when the pyrexia had been overcome and the convulsions had set in, and had no hesitation in referring them to the exhansted state of the heart, which could not be felt, and could scarcely be heard, while the pulse was all but imperceptible. The fact that the patient could scarcely be raised in bed without bringing on an attack of convulsions was of decisive significance."

I have at present under observation a gentleman, aged 52, who consulted me on account of shortness of breath on going up stairs, and especially on going up the steps from the railway station. He had bacome so nervous on the subject that his heart began to palpitate and his breath to go before he came to the foot of the stairs. He had palpitation also occasionally at night. He looks the picture of health and younger than his years; is stout and of rather high colour; eats and sleeps well; and has a regular action of the bowels. He rides a tricycle, and has much fresh air and exercise. The pulse is frequent, 90 to 108 , small, short, and extremely compressible. The heart is partially covered by lung, does not appear to be enlarged, and gives no impulse or apex beat; the sounds are short and approximated, the second following the first too quickly. The first sound is audible, not only at the apex and right second space, but also in the neck, where both sounds are remarkably distinct. He spoke of having had a fainting attack, and, when this was inquired into, it was described as having occurred as follows. It was in August, and he had had a tricycle ride, had washed and changed, when he bethought him he would like a glass of beer, which he had not tasted for years. Shortly afterwards he felt a peculiar tingling in his feet, and had just time to lie down when he lost consciousness, and did not come to himself for forty minutes or more. This could not have been a syncopal attack, and, whether convulsions occurred or not, was epileptoid. It was further learnt on inquiry that he had had several similar attacks within the last few years, always beginning with the tingling sensation in the feet, and attended with complete loss of consciousness, lasting, on an average, twenty minutes. He had had no fits of any kind as a boy, or until the occurrence of those referred to.

I am not without hope that a careful study of the pulse, and of conditions of the circulation made known through it, may be of service in furnishing indications for the treatment of epilepsy. It is certainly attended with interest, and I think it throws light on different forms of epilepsy, and serves as a guide in prognosis.

Epileusy is apparently the result of instability in the highest nerve centres, the cells of the cerebral cortex permitting of an indiscriminate general or partial discharge upon lower centres of nerve force, which normally ought to be set free, only in definite degree and in welldefined direction, in response to given stimuli. Such instability is obviously a nutritional defect, which may be due to the inherent want of constructive energy in the nerve-cells themselves, or may be the result of blood which cannot furnish the proper pabulum, or of an iuadequate supply of blood. Even in the case first supposed a regular and ample supply of blood, under sufficient pressure to cause a due exudation of nutrient material and of proper composition, will be im. p rtant, while in the other conditions supposed it will be remedial, Bit, given more or less of instability, this does not of itself start the convulsive explosion ; some exciting cause must be applied. At one time this was supposed to be arterial spasm in certain convolutional areas; but this hypothesis, which never seemed to me to be tenable, has gone out of fashion. There are, however, facts which seem to show that circulatory conditions have much influence in determining the occurrence of attack. For example, the great frequency with which fits come on in the night, sometimes on first going off to sleep, when the horizontal position and the anæmia of the cortex attending sleep produce great changes in the intra-cranial circulation, or more frequently towards morning, when the general circulation has slackened down, as it does during sleep. Another favourite time for attacks is soon after rising in the morning, when circulatory changes of a reverse kind take place.

It is not my intention to discuss the questions which might be raised on the subject here alluded to, but $I$ desire to call attention to a provisional conclusion to which I have been led by my own limited observation. This is, that in essential epilepsy-the epilepsy which comes on during adolescence, the epilepsy met with in neurotic families, and in which the nerve-cells may fairly be assumed to be inherently unstablo-the arterial tension is low and variable or fluctuating.

I am unable to affirm that when the attacks are suspended, as they may be for months, the pulse-tension is improved, but it is worthy of remark that pregnancy is not infrequently attended with immunity from fits, and as is well known, one effect of this condition is high tension in the pulse.

On the other hand, when the pulse-tension is decidedly and constantly above the average, it has seemed to me that the epilepsy has been amenable to treatment. Senile epilepsy is, according to $\mathrm{my}$ experience, associated with high tension, and scarcely ever fails to yield to a regulated diet with a restricted amount of animal food and little stimulant, aperients and other eliminants being given, according to the requirements of the particular case. Epilepsy with high arterial tension often comes on at a later period than the epilepsy, which has its source in a radical weakness of the nervous system, and, in most of the cases I have met with, the first fit has occurred after the age of 20 , and not uncommonly there have been peculiarities, such as a number of attacks close together, with long but irregular intervals, or some well-marked exciting cause. The fits may, however, date from the usual age at which epilepsy sets in. Many years since, a surgeonmajor in the army brought his son to me on account of epileptic attacks, which had compelled him to leave the navy. He was a fine, strong, healthy-looking lad, and had a large pulse not easily compressed. Under treatment the fits, which had been so frequent, ceased to come on. He studied for and got into Sandhurst, obtained a commission in an infantry regiment, and has since served through the Afghan campaign. So far as I know he has only had two attacks since he entered the army, one in Afghanistan, when, together with trying work, he had bad food and water, and another in Ireland after great fatigue and a bout of dissipation.

I have several times seen violent maniacal delirium associated in such a way with convulsions as to suggest that a minor degree of the disturbing influence which caused convulsions had given rise to the maniacal excitement-after bleeding, for example, for uræmic convulsions-before and aiter, or apparently instead of uræmic convulsions-in syphilitic disease of the brain. In the following case the connection between the state of tension of the pulse and ungovernable excitement was recognised by several observers over a long period. The patient was under the care of Dr. Ranking, at Tunbridge Wells, and Dr. Marcus Allen, at Brighton, and in town under Dr. Seton and Dr. Coates, with whom I saw her weekly from March to July, 1884, and again in March, 1885. Dr. Ranking, who has kindly supplied me with the particulars, was called to her in May, 1882, when she was convalescing from a third attack of slight (left) hemiplegia. She was very nervous and apprehensive, and had dilatation of the heart, with an unstable pulse of virtual tension. During the summer she had several anginoid attacks, which were relieved at once by nitro-glycerine, and in the winter attacks of congestion of the lungs, with partial suppression of urine and albuminuria. One day in July, 1883, she became suddenly excited, with delusions, which lasted some time, but went off after one-hundredth of a grain of uitro-glycerine, and she slept. Later in the summer she got into an excited, unsettled, suspicious, and violent state, which persisted, together with high tension of the pulse. Once she was comatose for twenty-four hours, but recovered after nitro-glycerine, and at once became maniacal. In the winter 1883-4, she was under the care of Dr. Marcus Allen, at Brighton. It was found by observation that her mental condition was always worst when the pulse-tension was high, and that the only way of keeping it down was to cut off all meat, and feed the patient chiefly on milk. This was confirmed by our experience when she was brought to town. When the tension was high, she was suspicious, abusive, violent, and unmanageable. When it was normal, she was cheerful and tractable. Mercurial aperients were constantly needed in order to keep down the tension and regulate the bowels. Ultimately she ditd in March, 1885, with symptoms of meningeal hæmorrhage.

With advancing years there comes a liability to many forms of cerebral affection. Some are examples of structural change which are 
clearly traceable to interference with the normal blood-supply. Such changes are local or general softening from thrombosis of individual arteries, or general obstruction to the blood-supply from atheroma affecting all the cerebral arteries. The local arterial change is not the sole factor in the production of the lesions. A state of blood which renders it prone to coagulate or deposit fibrin will predispose to the formation of a thrombus at any point where the walls of the artery are diseased, and want of propulsive power in the heart, or other cause of languid movement in the blood, may antedate the occurrence of degenerative changes attributable to widely distributed disease in the vessels. But an impeded cerebral circulation may, in course of time, so far modify the nutrition of the brain as to give rise to functional affections without structural lesions; and this, in my opinion, is the mode of causation of some forms of insanity which come on late in life, such, for example, as senile melancholia.

The term senile may have two meanings-it may designate an age, or be descriptive of a kind of change. The term "senile" is unobjectionable if it is meant to apply simply to the period of life at which this affection is met with, but it is of ten understood to mean a certain character of change, and its frequent employment to designate degeneration has led to the common idea that senile and degenerative are convertible terms. This does harm in two ways. Senile changes, if degenerative, are irreversible, and if this view is taken of dementia or melancholia, there will be no object in carefal investigation of associated conditions, no other cause than senile decay will be looked for, and no individual treatment will be adopted, based upon the peculiarities of different cases. Furthermore, the reproach of insanity or of neurotic tendencies may be sttached to families, when the derangement of the cerebral functions may be as much a result of vascular disease as cerebral hæmorrhage. A family liability to melancholia may consist in hereditary high tension of the pulse, just as a liability to apoplexy may be due to family gout.

Now the complete recovery witnessed in many cases of melancholia is proof that there cannot have been any structural degeneration, and an example like the following may be worth relating.

Some two years since I was asked to see, periodically, a gentleman, aged about 60 , who had for four or five years been under the Commissioners in Lunacy on account of melancholia. He had had delusions as to conspiracies against his life, but such delusions as remained related chiefly to wilful and malicious injury inflicted upon him, and attempts to destroy him in an asylum. He spent nearly all his time in bed, scarcely ever left his room, and never went out of doors. He was well nourished, and, except that he was etiolated by his long confinement to the house, looked well, but the pulse was extremely small, soft, and short, and the action of the heart extremely weak. He had eczema, and suffered from constipation and want of appetite, and treatment was prescribed for the relief of these symptoms. His general health improved, but his mental condition remained much the same, and, in particular, the death of a son made little impression on him. In June, 1886, he suddenly shook off all his delusions, and became perfectly sane and cheerful. With this the pulse improved, but never reached an average volume or tension, and in October he remained well, and, after examination by Dr. Maudsley, was discharged from his Iunacy. Unfortunately, on February 24th of this year, he became aphasic from thrombosis of the vessels supplying the cortical speech centie.

Pulse and Melancholia. - The connection between melancholia and its allied ruental states and conditions of the circulation is more direct and decided than can be traced in epilepsy.

An unbroken series of gradations can be traced from the irritability and depression of spirits attending functional disorder of the liver, up to complete melancholia, with delusions. In a case of temporary hepatic derangement, the state of the temper and spirits might be attributable to the retention in the blood of the impurities which tinge the eyes and complexion, this acting as a poison; or to some reflex influence, inhibiting cerebral functions, or deranging the cerebral circulation by setting up contraction of some of the arteries. When, however, the mental depression is more pronounced and persistent, these explanations are found not to apply; there may be, in the first instance, constipation, a furred tongue, sallow complexion, large liver, etc. But when these evidences of deranged function are removed, the mental condition does not clear up. If the symptoms, therefore, are due to any somatic cause and are not the outcome of a primary cerebral affection, this cause is something more persistent than the functional derangement or reflex disturbance mentioned. This has appeared to me to be protracted arterial tension, or, if it is not itself the cause, it is at least the index of the condition of the state of system on which the mental condition depends.

The method by which high arterial ten bral functions may be conceived to be as follows. The resistance in the peripheral vessels calls for increased contractile force on the part of the left ventricle, and there is a response by a certain degree of hypertrophy. In the course of years, however, the resistance increases, degeneration of the capillaries and thickening of the arterioles being superadded to the original loss of due relation between blood and tissues, while the beart no longer gains in strength. With, then, the same or somewhat diminished driving power and the resistance increased, there will be a slower onward movement of the blood. The pulse may be equally strong - may even seem to be more incompressible-but the capillary circulation will be sluggish. This will be the case throughout the system, but it will not give rise to appreciable effects in most of the structures and organs; in the brain, however, as has already been said, functional activity and efficiency are absolutely dependent upon a due supply, not only of nutrient material, but also of oxygen, and this fails when the flow through the capillaries is sluggish.

In a very large proportion of the cases of melancholia coming on late in life, the evidence of persistent high tension of the pulse has been most marked, and when this has been the case it has seemed to me that persevering endeavours to diminish the peripheral resistance, and at the same time to strengthen the action of the heart, have been more successful than any other line of treatment. The object is so to relieve the heart that it may no longer be mastered by the obstruction in the general capillary circulation; there will then be a general acceleration of the flow of blood through the tissues, and by the increased supply of blood to the brain its nutrition and functional efficiency may gradually be restored. The possibility of this result and the time required for its attainment will depend on various conditions. There must be a capability on the part of the heart to resume its control over the circulation, it must not be degenerate or worn out. The state of the cerebral arteries, again, will have an important influence; if they are extensively diseased, the access of blood to the convolutions may be barred even when the circulation elsewhere is good. Further, the change in the nervous elements must not have gone too far ; the longer they have been subjected to the deteriorating influence of imperfect blood-supply, the longer will be the time required for the reversal of the effects. Of these three sets of conditions we can only estimate the first by examination; with regard to the others, the basis of our judgment must be the history. Speaking generally, the more acute the attack and the shorter its duration, the better will be the chances of recovery.

Cases of this kind, many of which have come under my notice, do not lend themselves to narration, especially when seen in consultation only once or twice, and I shall not attempt to bring instances before you. I may, however, relate an occurrence with regard to one sucha most distressing case of religious melancholia in a lady of about 60 , with extreme high tension in the pulse. I had explained my views to Dr. Baines, with whom I saw the patient, and had recommended, among other measures, a series of mild calomel purges, when the sister of the patient joined us, in order to learn our opinion. Before hearing this, however, she said there was one more fact which she ought to have told us-namely, that their mother, at very nearly the same age, had suffered exactly in the same way. It seemed as if my hypothesis of the relation of the melancholia to the state of the circulation was at once overthrown, and with it my favourable prognosis. "But," she continued, "in those days they gave calomel for everything; and it was prescribed for her, and she got quite well." Our patient also recovered-only, however, to relapse some time later.

Melancholia associated with extremely low pulse-tension has, in my experience, usually proved incurable, and has in several instances gone steadily from bad to worse to a fatal termination. The case related a few minutes ago is the only instance of recovery I have met with.

I announced that this lecture would be devoted to the pulse and cerebral affections, but I may be permitted to refer to an affection of the lower end of the spinal cord, especially as it furnishes a sort of parallel to the production of melancholia by derangement of the circulation.

Our late colleague, Dr. Moxon, whose loss those who knew him well will never cease to deplore, pointed out in his brilliant and original Croonian lectures, six years since, that common paraplegia, as he called it, was explained by anatomical facts. The spinal cord receives its blood-supply by means of the arteries which reach it along the nerve-roots. These, in consequence of the downward elongation of the spinal canal beyond the cord, get the more oblique and longer from above, downwards, and at the cauda equina are many inches in length, so that the arteries of the lumbar enlargement, which occupies the lower part of the dorsal division of the spine, have to 
travel upwards for this distance from the foramina in the lumbar and eacral regions. When, then, the circulation becomes languid, the mochanical difficulties of this arrangement make themselves folt. The symptoms attending the early stage of paraplegis due to failing circulation in the lumbar enlargement of the cord are very interesting. As the nutrition of the lower end of the cord begins to suffer, there is at first muscular weakness and loss of control over the legs only after a night's rest. The pationt has some difficulty in stan Jing and walking steadily when he first gets out of bed; but, after he has moved about a little, the legs regain power, and he can walk perfectly. A similar state of things is observed with regard to the bladder. $\mathrm{He}$ cannot pass water on rising, but, when he has had a little walking, he empties the bladder easily. Whenever he sits down for any length of time during the day, there is more or less impairment of mobility and strength in the lower extremities, which quickly passes off with movement. Sensation is not affected at first, but there may bo feelings of numbness. The coming on of the weakness during the night is due to the slackening down of the circulation which takes place during sleep, and is paralleled by the morning depression in melan. cholia and debility.

I have met with this train of symptoms at the two extremities of high and low pressure. When there is high pressure it is that the general resistance in the periphery has overtaxed the powers of the heart, so that the whole circulation is sluggish, and the languid flow is most easily brought to a standstill where the difficulties are greatest. Usually the symptoms come on very gradually, but I have known their onset to be determined $y$ the occurrence of acute dilatation of the heart. When the tension is low and the heart weak, no explanstion of the impeded circulation is needed.

I end these lectures with a feeling that I have dono but scanty justice to the subject, but with feelings also of gratitude for the patience and indulgence with which my poor attempt has been received.

\section{THE LUMLEIAN LECTURES ox \\ THE PATHOLOGY OF INTRA-UTERINE DEATH. \\ Delivered at the Royal College of Physicians of London, March, $188 \%$. \\ BY W. O. PRIESTLEY, M.D., F.R.C.P., LL.D., Consulting Physician to King's College Hospital; and late Professor of Obstetric Medicine, King's College. \\ Lecture II.-Diseases of Fetal apprendaks. [Concluded from page 718.]}

Morbid Changes in the Chorion.-The pathological change affecting the outermost true fotal envelope or chorion which has received most attention is what is commonly called "cystic or vesicular or hydatid degeneration." In this affection small or large quantities of cyst-like bodies are expelled at intervals from the uterus of the pregnant woman, their expulsion being attended with hæmorrhage, and commonly with the discharge of a large quantity of serous fluid of pinkish colour, which has been compared to red-currant juice. Madame Boivin ${ }^{25}$ stated that she found this disease occurring only twice in 20,375 pregnancies, but I suspect this account does not represent the true frequency of the affection, for most accoucheurs in farge practice have met with it, and specimens of cystic chorion in its various stages are to be found in almost all our museums. In its carlier phases it is not uncommon, but then may be readily overlocked. When fally developed the appearance of the growth is very remarkable, and must at once arrest the attention of the modical attendant. Although commonly thrown off at first in detached portions, a time comes when uterine action fully sets in, and then a large quantity of cysts may be expelled in one mass, which, in some instances, is sufficient to fill a large basin. The vesicles or cysts of which the mass is composed vary from the size of a millet soed to that of a grape, and these are intimately united together at various points by thin stems or pedicles. They have been compared to bunches of grapes, but the cysts do not necessarily terminate the stem on which they are suspended like grapes, but are united in a plexiform arrangement on $\theta$ with another in a sort of network.

In Parc's Surgery it is reconnted "that the Countess Margaret,

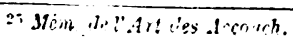

daughter to Florent IV, Earl of Holland, and spouse to Count Her. man of Heneberg, on Good Friday, in the year of our Lord 1276, and of her age 12, brought forth at one birth 365 infants, whereof 182 are said to here been males, as many females, ard the odd one an hermaphrodite, who were all baptized, those by the name of John, these by the name of Elizabeth, in two brazen dishes, by Don William, Suffragan Bishop of Treves" It is added : "the basins are still to be seen in the village of Losdun, where all strangers go (on purpose) from the Hague, being reckoned among the great curiosities of $\mathrm{Hol}$ land." This account is not regarded by modern authorities as a pure invention. Ambrose Pare was eminently honest, and these 365 children are now regarded as having been merely vesicles of a cystic chorion, magnified into infants by someone whose interest it was to promulgate the illusion.

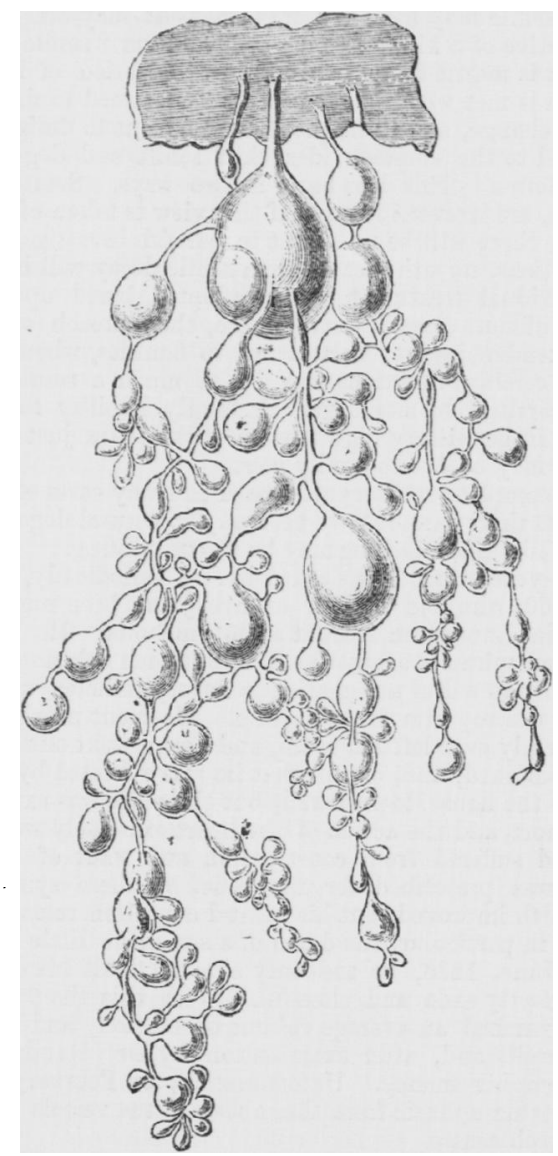

Fig. 3.-A portion of cystic chorion as seen with the naked eye. The arrangement of the vesicles is scen and also their attachments to the chorion membrane (Ercolani).

The published literature on this single disease of the chorion is more extensive than of any affection of the fotal membranes, and both detashed observations and separate monographs exist in several different languages. Cloquet, ${ }^{23}$ Percy ${ }^{27}$ and Boivin regarded the vesicles of the chorion as true acephalocysts; but it has heen abun. dantly proved that they are not so, being furnished neither with hooklets nor other minute structures characteristic of ti ue hydatids. Bidlos and Soemmering believed cystic chorion to be a disease of the lymphatic vessels ; and Bartolin, Müller, and Cruveilhier ${ }^{23}$ a disease of the blood-vessels. Ruysch ${ }^{29}$ attributed the formation of the cysts to accumulation of fluid in the cellular tissue which unites the vascular tunics of the foetal membranes.

Nearly all modern authorities ayree in regarding them as the results of pathological changes of one kind or other in the villi of the chorion. The single exception, I think, is Ancelet, who in 1868 published a paper in the Gazetle des Hopitaux, and he there reverts to an old idta that the hydatid mole is a disease of the decidua.

$$
\begin{aligned}
& \text { 2) No. } 1 \text { de la Faune des Miéd. } \\
& \text { 2: Anoien Journ. de Med., } 1793 . \\
& \text { 3' Vide Charpentier, Maladies du Placent I. } \\
& \text { 2' Gbser. Anat. Clin., 1691. }
\end{aligned}
$$

